\title{
Mapping resource effectiveness across urban systems
}

\author{
Ling Min Tan $\mathbb{D}^{1 凶}$, Hadi Arbabi $\mathbb{D}^{1}$, Danielle Densley Tingley ${ }^{1}$, Paul E. Brockway $\mathbb{D}^{2}$ and Martin Mayfield ${ }^{1}$
}

Cities and their growing resource demands threaten global resource security. This study identifies the hotspots of imports in cities to redirect resources to where they are most needed, based on the system overall resource effectiveness to maximise the use of all resources available. This paper develops a taxonomy of resource-use behaviour based on the clustering patterns of resource utilisation and conversion across interconnected urban systems. We find high tendencies of consumer-like behaviour in a multi-city system because tertiary sectors are concentrated in urban areas while the producing sectors are located outside and hence, results in high utilisation but low output. The clustering taxonomy emphasises that the absence of producers in the system causes cities to rely on the imported resources for growth. Cities can be resource-effective by having a more diversified industrial structure to extend the pathways of resource flows, closing the circularity gap between the suppliers and consumers.

npj Urban Sustainability (2021)1:20; https://doi.org/10.1038/s42949-020-00009-3

\section{INTRODUCTION}

The United Nations Environment Programme (UNEP) has warned further urbanisation could raise the annual intake of resources to nearly $90 \mathrm{bn}$ tonnes through urban material consumption by 2050, a $125 \%$ increase from 40 billion tonnes in $2010^{1}$. As the demand for resources continues to grow, resource requirements of urban areas have significantly exceeded the biocapacity of the planet, as an estimated four out of nine planetary boundaries have been surpassed causing irreversible change to the environment ${ }^{2,3}$. Revisiting the City's Limit report ${ }^{4}$, the ecological footprint of London is 49 million global hectares, which is equivalent to 42 times the city's biocapacity and 293 times of its land area (twice the size of the UK). If everyone in the world consumed natural resources at the same rate as the average person in the UK, three planets would be required to support this standard of living ${ }^{5}$. To achieve a long-term sustainable living environment in cities, urban consumption must be regulated through more effective ways of using the resources available to reduce the demands for new material extraction. This means a global transition towards lowcarbon resource-effective cities is instrumental in urban governance to align with the sustainable development goals ${ }^{6}$.

The concept of urban metabolism (UM) was introduced by Wolman in 1965 as an analogy between urban systems and natural biological systems to model resource use and waste produced in cities ${ }^{7}$. The international community of industrial ecologists has contributed to developing and popularising the techniques and implementation of urban resource assessment tools using the UM framework ${ }^{8}$. These include ecological network analysis $^{9-11}$, material flow analysis ${ }^{12-14}$, life cycle assessment ${ }^{15,16}$, input-output analysis ${ }^{17,18}$, and studies of the food-water-energy nexus in urban systems to manage material production and consumption in cities $^{19}$. Adaptations of industrial ecology methods with the framework link the concept of UM and ecosystem management to study the hierarchical metabolism of energy and material flows in cities in order to sustain a growing urban ecosystem ${ }^{20-22}$.

Despite the sheer volumes of literature and methodologies on tracking and analysing resource flows, none of these is conceived to address the emerging problems related to the quality of resource use and circularity of resource flows in urban systems that threatens the sustainability of our cities and societies. In the UM framework, current knowledge of resource-use behaviours in urban systems is still far from sufficient to move our cities and communities towards sustainable consumption due to a lack of understanding in the energy transformation processes and resource exchanges within the flow network of an urban ecosystem. In fact, to fill this gap, one promising avenue is to use the open system network approach, which incorporates ecosystem theories into urban network settings providing an interface where cities can be managed as ecosystems to drive development in a more sustainable, liveable and resilient direction. The network approaches share similar principles with the practices of cross-sector circular economy (CE) to retain and circulate resource flows within the urban systems for as long as possible ${ }^{23}$. Implementation of CE principles at urban level helps to facilitate the transition from linear metabolism to circular metabolism in order to relieve the pressure caused by resourceintensive economic activities in cities, healing the cities by making use of resources locally ${ }^{20}$.

From an ecological-thermodynamic perspective, cities are open systems that import resources to sustain their socio-economic processes and enable economic growth ${ }^{24}$. Following the Second Law of Thermodynamics, entropy always increases in an irreversible process, so the total entropy of the universe is continually increasing ${ }^{25}$. Entropy production measures the amount of energy wasted and no longer available to deliver work done due to differences in resource quality. In non-equilibrium open systems, resource intakes prompt the systems to increase entropy production and energy degradation as their inflows increase, this behaviour is known as self-organisation in dissipative open systems. In urban contexts, this results in higher work potential available in the urban systems with increasing resource intakes when the cities grow ${ }^{25}$. The self-organising behaviours of open systems essentially form the foundations of the open system network effectiveness analysis (OSNEA) framework to assess the abilities of the system to dissipate the 'exergy' resource available through cascading transformation processes in an urban system ${ }^{26,27}$. The term 'exergy' is used to account for the usefulness, or the potential to do work, of the metabolic resource flows. The use

\footnotetext{
${ }^{1}$ Department of Civil and Structural Engineering, University of Sheffield, Sheffield S1 3JD, UK. ${ }^{2}$ School of Earth and Environment, University of Leeds, Leeds LS2 9JT, UK.

丝mail: lingmin.tan@sheffield.ac.uk
} 
OSNEA conceptual diagram

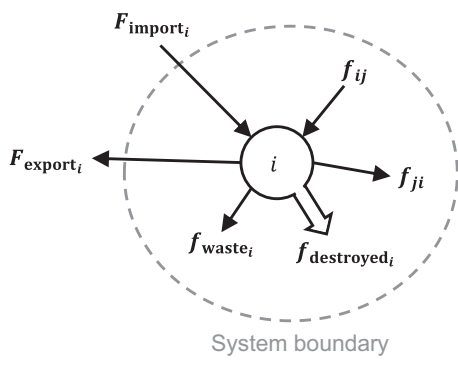

For all $m$ nodes in the network,

Effectiveness of utilisation, $\varepsilon_{\mathrm{U}}=\frac{\sum_{i=1}^{m} f_{\text {destroyed }_{i}}}{\sum_{i=1}^{m} F_{\text {import }_{i}}}$

Effectiveness of conversion, $\varepsilon_{\mathrm{C}}=\frac{\sum_{i=1}^{m} F_{\text {export }_{i}}}{\sum_{i=1}^{m} F_{\text {import }_{i}}}$

From the effectiveness plot,

Overall resource effectiveness, $R=\sqrt{\varepsilon_{\mathrm{U}}^{2}+\varepsilon_{\mathrm{C}}{ }^{2}}$

Resource effectiveness balance, $\theta=\tan ^{-1} \frac{\varepsilon_{U}}{\varepsilon_{C}}$ b

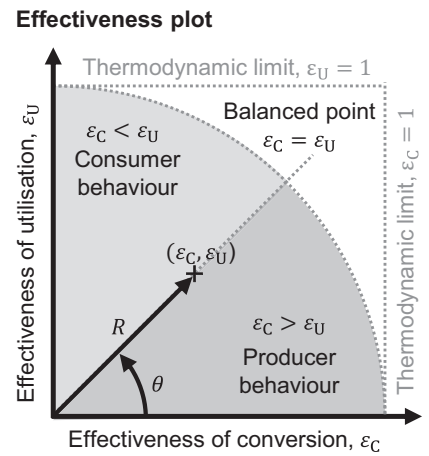

Fig. 1 Conceptual diagrams of the OSNEA framework. a Schematics showing the exergy flow balance at a sector $i$ to explain the definition of $\varepsilon_{\mathrm{U}}, \varepsilon_{\mathrm{C}}, R$ and $\theta$. b An effectiveness plot to assess cities' resource sustainability performances based on of $\varepsilon_{\mathrm{U}}$ and $\varepsilon_{\mathrm{C}}$ indicators, image adapted from Tan et al. ${ }^{27}$.

of exergy as a metric for resource effectiveness is subject to debate $^{28}$. It is an extensive thermodynamic property derived from the studies of energy transformation. Although the concept is sometimes employed in other fields outside the realm of energy systems, it offers at least a qualitative descriptor to account for the availability of work and irreversibility of thermodynamic processes for assessing resource efficiency and environmental sustainability $^{29}$. This framework, as shown in Fig. 1, provides an exergy-based assessment for urban resource sustainability with a set of performance metrics, namely, the effectiveness of utilisation, $\varepsilon_{U}$, and the effectiveness of conversion, $\varepsilon_{C}$, to quantify how much of the usefulness of the resources available in cities is effectively extracted and utilised $\left(\varepsilon_{U}\right)$ or converted to export in exchange for capital inflows $\left(\varepsilon_{C}\right)$ through urban processes ${ }^{30}$.

For producing sectors or producers in an urban ecosystem, higher $\varepsilon_{\mathrm{C}}$ and processing efficiencies are preferred to improve the system transformation processes for minimal costs and waste emissions. In contrast, effective consumers with higher $\varepsilon_{U}$ are more capable of making use of the resources available to maximise their work done and reduce the needs for new extraction or import. As shown in Fig. 1, the system exhibits a producer behaviour when $\varepsilon_{U}$ is smaller than $\varepsilon_{C}$, or a consumer behaviour when $\varepsilon_{U}$ is greater than $\varepsilon_{C}$. From these, this method models cities as open system networks to assess the performances of urban systems in making use of the resources available, and promote higher effectiveness of resource use in cities to retain the resource flows in the system through longer flow circulation in order to reduce the imports and extraction of new materials. The trajectory of effectiveness through time can also be used to describe the relationships between the producing and consuming sectors in the city and to gain an understanding of how the system maintains the ecological balance (when $\varepsilon_{U}$ and $\varepsilon_{C}$ are equal) between the resource producers and consumers in the ecosystem. This is important because an ecological balanced system possesses healthy resource control and dependency relationships within the economy and supply chains to manage and regulate the distribution of resources among the producing and consuming sectors in the city and reduce the development gaps between economic sectors for long-term sustainability ${ }^{11}$. This also applies to the cities' interactions with their surroundings as excessive extraction of natural resources beyond planetary limits could disrupt the balance of the ecosystem and exert irreversible effects on the environment.

This work aims to address sustainability challenges related to resource use in cities by quantifying and mapping resource effectiveness across whole urban systems to provide an understanding of the interdependencies within the systems of cities. In our case study of Great Britain's urban systems, we evaluate the effectiveness of resource use in cities using OSNEA and identify the clustering taxonomy of urban resource use based on their roles in the wider interconnected networks. This will shed light on the planning strategies for resource allocation across the whole urban systems by identifying the hotspots of imports in the system and redirect resources to where they are most needed for better use. Effective resource-use behaviours help to achieve the objective of sustainable cities by maximising the use of all resources available through longer flow circulation and ultimately, reduce demands for new material intakes in future urbanisation without compromising economic outputs and system productivity. The rest of the paper is structured as follows: firstly, the results present the case study system of Great Britain and the open system network representation of the urban networks showing the intercity and intra-city resource flows across the whole system. Secondly, the overall results of resource effectiveness and balance are shown together with the spatial variation of exergy intensity of economic activities in all cities. These contribute to the development of a clustering taxonomy of resource-use behaviour to enable a targeted investigation of each cluster to identify the leverage points for policy interventions based on the unique characteristics of the clusters. This is followed by a discussion to highlight the significance and explore the potential implications of this study. Lastly, the method provides the procedures taken in this study for the generation and interpretation of the findings.

\section{RESULTS}

Case study of Great Britain's urban system (2000-2010)

The urban systems of Great Britain (GB) contain 38 urban audit functional urban areas (FUAs) across England, Wales and Scotland $^{31}$, as shown in Fig. 2. The urban audit boundary defines the scope of this case study which includes the core central city of each FUA and its commuting zones ${ }^{32}$. In this definition, the wider FUAs may consist of multiple local administrative units (LAUs), the lowest administrative level of local governing councils, as data collecting units. The resultant data of population and gross value added (GVA) of the FUAs are obtained by combining all LAUs within the urban boundaries. In this case study, agglomeration heterogeneity of UK industrial mix draws disparities across the FUAs contributing to varying demands and behaviours in terms of resource use in cities ${ }^{33}$. Note that the usage of phrases 'FUA' and 'city' are not interchangeable as 'FUA' refers to a specific urban area in GB while 'city' is used more generally and can apply to any urban area outside the case study system.

The urban systems interact with the external surroundings by importing resources from the hinterlands and trade partners abroad and exporting products and services in exchange for 
a

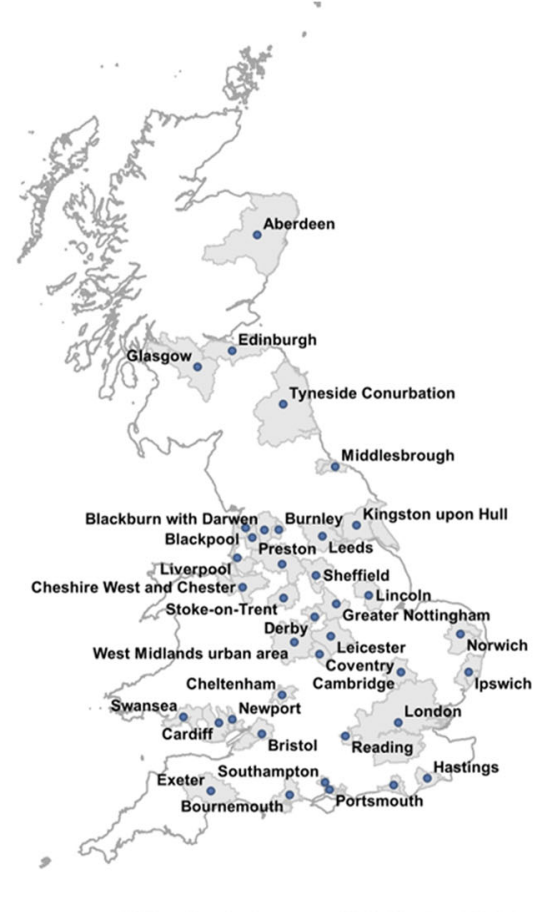

38 Functional urban areas (FUAs) in Great Britain
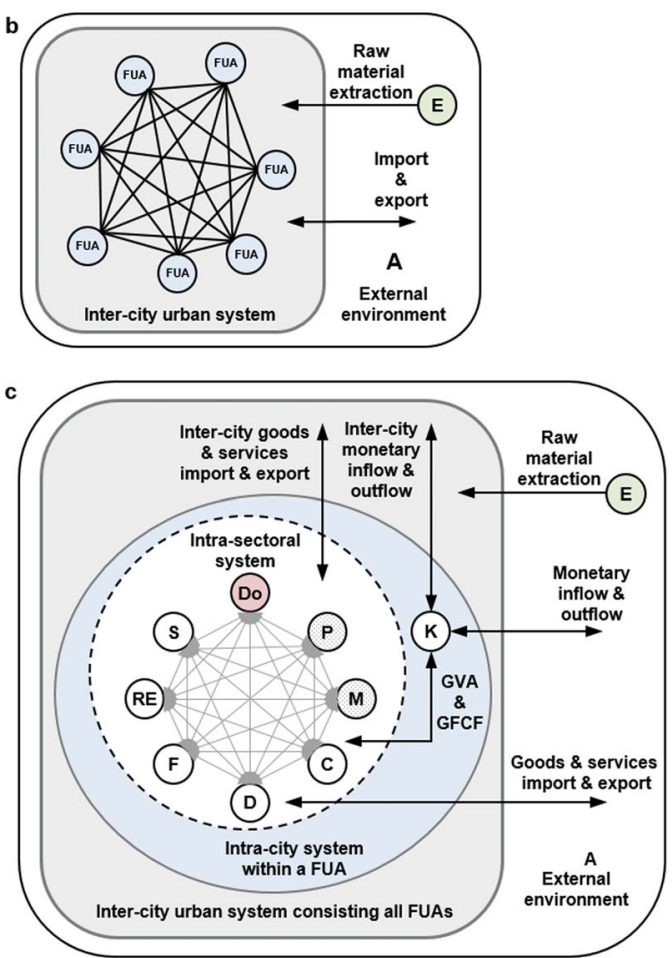

Notations:

Intra-sectoral system

P Goods handling sectoral node Production (P) Manufacturing (M)

C) Intra-system node: Distribution (D) Finance services (F) Real Estates (RE) Other services (S)

Do) Domestic sector (Do)

Intra-city system

(K) Capital reserve

Inter-city system

(FUA) Functional Urban Area

IC Inter-city urban system

External environment

A Abroad

(E) Natural environment

Fig. 2 Schematic network representing the urban system of Great Britain. a All 38 functional urban areas (FUAs) in Great Britain are included in this case study to analyse effectiveness performance of system as a whole. $\mathbf{b}$ The FUAs are connected by intercity input-output flows as resources exchange among the cities to present a whole urban system network. The system interacts with the external surroundings via imports and exports from abroad (A). Local extraction activities are considered as raw material imports into the urban system from the natural environment (E). c Within each FUA, the intra-sectoral system consists of all socio-economic sectors in the cities and the linkages between the sectors including the domestic sector (Do), which provides labour work to support the economic activities via employment. The capital node $(K)$ is also a part of the intra-city system to account for inflows and outflows of monetary resources.

capital inflows. At intra-city level, connecting economic sectors via input-output transactions, together with the extended-exergy accounting method to include domestic labour and capital contributions to the economy, forms an intra-sectoral resource flows network within each city. Intercity flows are also added to the total imports and exports for each city within the urban systems. To model urban systems as open system networks, the total resources available in the cities, which consist of imported goods and services, are accounted for in the form of exergy for physical goods and extended-exergy for labour and capital flows.

Resource effectiveness and balance

We use an open system network effectiveness analysis (OSNEA) for a thorough investigation of resource use in the socio-economic processes of the urban system ${ }^{27}$. The effectiveness of utilisation $\left(\varepsilon_{\mathrm{U}}\right)$ reflects the consumer behaviour by assessing the network's ability to dissipate the imported resources through consumption activities whereas the effectiveness of conversion $\left(\varepsilon_{C}\right)$ reflects the producer behaviour by assessing the ability to turn biophysical resources into economic gains. These provide a new conceptual understanding of urban sustainability based on the resource-use behaviours exhibited throughout the urban system.

The effectiveness plot in Fig. 3a shows the system performance by plotting the trajectories of $\varepsilon_{U}$ and $\varepsilon_{C}$ through time. We assess the overall resource effectiveness $(R)$ by measuring the radial distance on a polar coordinate system to evaluate the overall performance of the system in making use of the resources available for both utilisation and conversion purposes. We also assess the overall effectiveness balance $(\theta)$ by measuring the angular coordinate to give a quantifiable measure of the balance between the production and consumption activities in the whole system.

The effectiveness plots in Fig. $3 b$, c show decreasing $\varepsilon_{U}$ and increasing $\varepsilon_{\mathrm{C}}$ over the years from 2000 to 2010. By taking the mean values of $R$ and $\theta$ for all the FUAs in the urban system, the values decrease steadily throughout the period with a slight spike in the mean values in 2009. This means the overall effectiveness performance has decreased from 2000 but the system has become marginally more balanced $\left(\theta=45^{\circ}\right)$ in 2010 . This suggests a compromise between the producing and consuming sectors to optimise system effectiveness with lower utilisation (lower $\varepsilon_{U}$ ) for higher capital inflows into the cities (higher $\varepsilon_{C}$ ) and economic growth. The drop in $\theta$ between 2003 and 2004 is due to declined imports of oil and gas products in Aberdeen from the extraction activities in the region ${ }^{34}$. On the other hand, maximum $\theta$ of the whole GB is found in Edinburgh (which peaked in 2005) due to very high consumer activities in the area, especially financial services ${ }^{35}$. These indicate that GB exhibits a more consumer-like behaviour as tertiary sectors such as finance and services are concentrated in urban areas and producing sectors located outside the urban conurbations.

We also assess the spatial variations between the resource-use taxonomy and sustainability performances of different cities. Mapping the import, export, $R$ and $\theta$ across the whole urban system of GB in Fig. 4 shows the spatial variation of urban sustainability performances and highlights the difference between cities in terms of their resource-use behaviours and trade patterns across the system.

Figure $4 \mathrm{a}, \mathrm{b}$ shows the distribution of average $R$ and $\theta$ across the whole urban system of GB. In general, the FUAs in England are more effective consumers with higher $R$ and $\theta$ than those FUAs in 

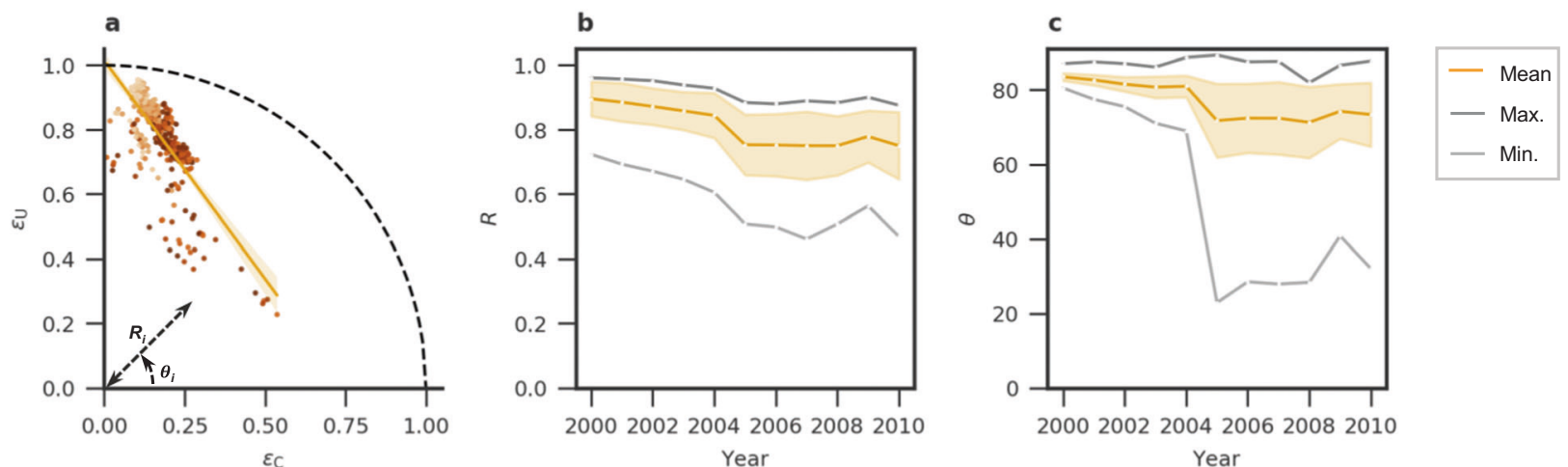

Fig. 3 Overall resource effectiveness and balance for urban systems in England, Wales, Scotland for years between 2000 and 2010 . a Plot of effectiveness of utilisation $\left(\varepsilon_{\mathrm{U}}\right)$ versus the effectiveness of conversion $\left(\varepsilon_{\mathrm{C}}\right)$. Colour saturation of markers increases with the year from 2000 to 2010. The dashed line shows the limiting envelope for the balance between the two effectiveness indicators. $\mathbf{b}$, $\mathbf{c}$ Temporal variations of the overall resource effectiveness and balance $(R, \theta)$ showing mean, standard deviation (shaded area), minimum and maximum values across the British urban systems.

a

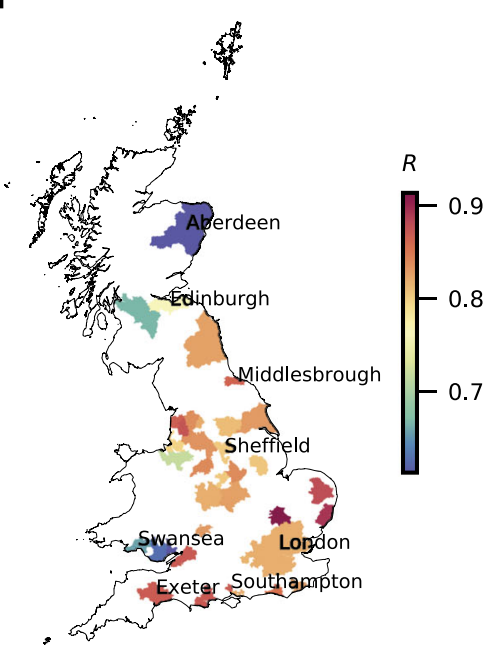

b

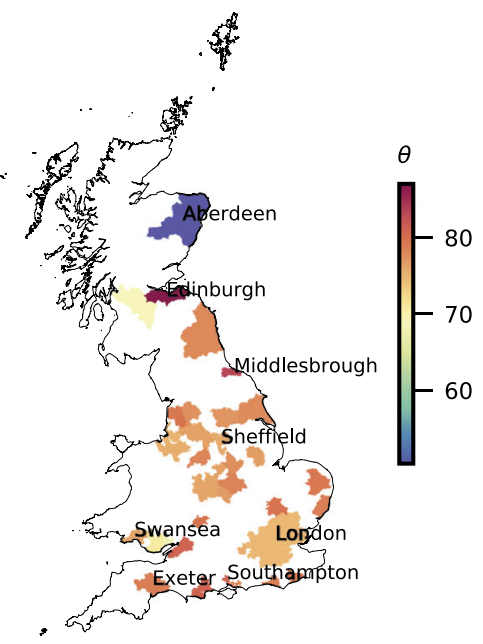

e

d

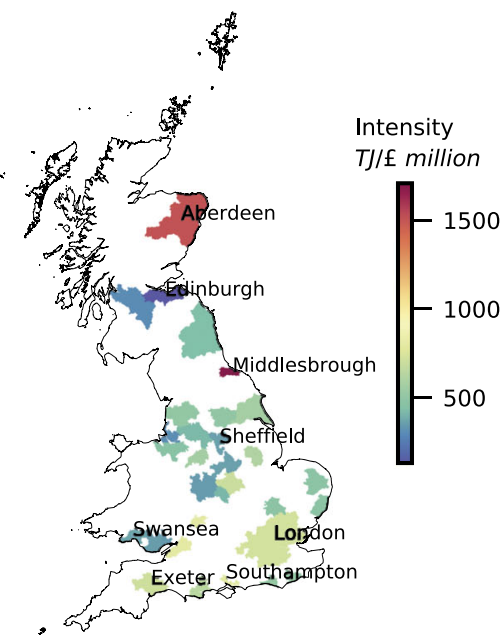

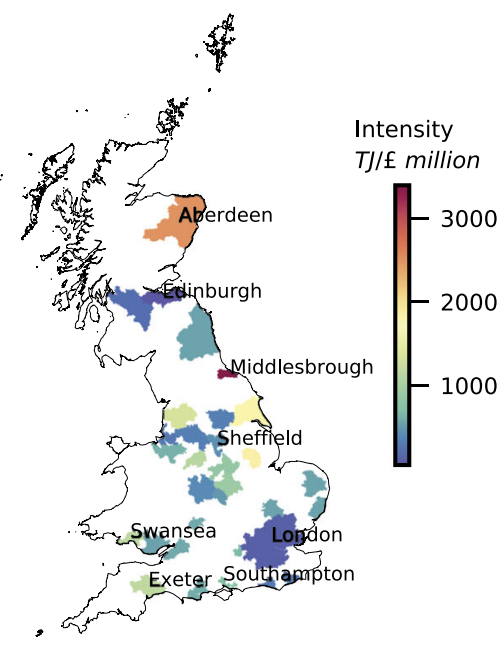

c

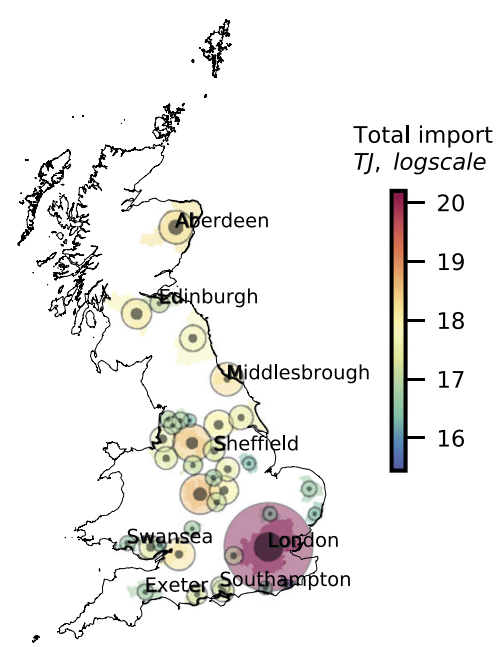

f

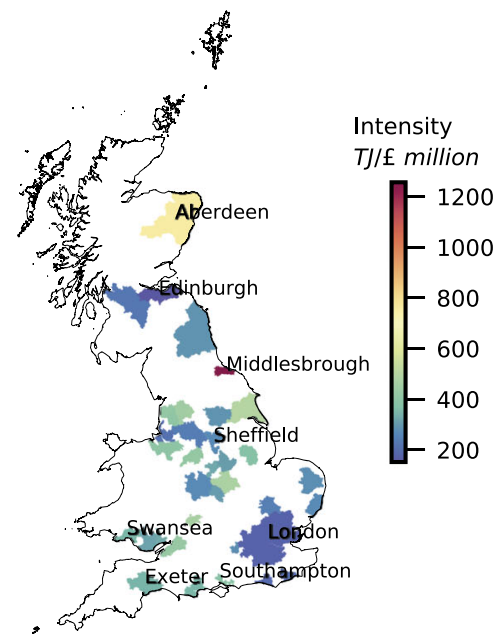

Fig. 4 Mapping resource effectiveness indicators across the urban system of Great Britain. a Average overall resource effectiveness, $R$, for 2000-2010. b Average resource effectiveness balance, $\theta, 2000-2010$. c cumulative imports (colour and size of the outer circle) and exports (size of the inner circle) for 2000-2010. d Average exergy intensity of manufacturing sector for 2000-2010. e average exergy intensity of finance services sector for 2000-2010. f Average exergy intensity of all sectors for 2000-2010. 
Wales and Scotland. In Scotland, Aberdeen has the lowest average $R$ and $\theta$ in the system. As one would expect given the size of the city, London has the largest import and export but not high resource effectiveness (Fig. 4c). Moreover, some areas are highly effective, such as Middlesbrough, Cambridge and Ipswich, but do not have a good balance due to extremely high utilisation and strong consumer traits. Aberdeen, however, demonstrates a good balance between the production and consumption activities due to high capital income from the oil and gas industry in the area.

Comparing the exergy intensity of economic activities in different cities gives a better-benchmarking criterion for evaluating states of resource consumption with respect to the economic productivity by measuring the amount of exergy imported by a city (or a sector) to generate a unit of GVA rather than referring to the gross exergy import. The exergy intensities of manufacturing and finance sectors across all FUAs in the system expose the differences in industrial specialisation between northern and southern regions of England (Fig. 4d, e). This highlights the northsouth divide in the UK due to the regional social and economic inequalities contributing to productivity and income gaps ${ }^{36}$. This can also be seen as the impact of having a more diversified economic structure especially the tertiary sectors in the south compared to the north with a larger income share associated with manufacturing industries. It is worth noting that although manufacturing activities should have higher exergy intensity than financial activities, the scale of colourbar for finance intensity has a higher maximum intensity than the manufacturing intensity. This is because of an imbalance in financial development among the cities causing high exergy intensity in financially underperforming areas such as Middlesbrough, Aberdeen and Lincoln with lower GVA from the finance sectors. This suggests the areas with lower economic productivity do not necessarily have lower resource intakes and may still be exergy-intensive because of a lack of economic diversity, especially in the tertiary sectors, to fulfil the utilisation and conversion of all resources available. In Fig. $4 \mathrm{f}$, the total exergy intensity includes import by the domestic sector which does not contribute to the GVA. Comparing the distribution of exergy intensity for all sectors to the sector-specific intensities shows the system consists of diverse specialisations and economic focuses causing the cities to exhibit unique characteristics and resource-use behaviours where cities with similar behaviours tend to cluster together in the flow network and have stronger influence on one another due to their common resource-use behaviours and resource interdependencies within a cluster.

\section{A clustering taxonomy of resource-use behaviours}

We further explore the resource-use behaviours of the cities through their clustering patterns, which allow us to categorise the cities and identify their common interests and needs for planning resource allocation across the whole system. We show a taxonomy of urban consumption providing a description of common characteristics for the areas within the same cluster. The patterns in Fig. 5 are identified using a clustering classification of the results of $R$ and $\theta$ spanning the whole duration of this case study. This provides a new insight into understanding how the cities are related in terms of the states of resource-use over time.

From analysing the differences in resource effectiveness performances among the FUAs, five clusters of different resource-use taxonomies are observed within the GB urban system. Further investigation of the clusters properties and their key characteristics help in designing the optimal solutions to improve the resource effectiveness of the cities and bring benefits to the whole urban system. Figure 6 shows the intensity gaps of each FUA throughout years 2000-2010 obtained by computing the difference between the national and individual FUA intensities in each year. The intensity gaps provide a yearly reference to the exergy import intensity of the FUAs compared to the intensity of the whole system and helps to identify areas with high intensities due to excessive imports or low economic productivity.

Cities in cluster 1, are in Wales and Scotland and identified to be import-dependent with the lowest import shares and exergy intensities among all the cities. Their effectiveness performances suggest the economic growth is limited by the amount of the resources available. This raises a global concern regarding the dilemma of balancing economic growth and resource sustainability in rapidly developing cities if the demand for imports increases. Hence, from a wider perspective of the whole urban system, more resources should be reallocated from the highintake-areas to prolong circulation within the urban system, provided that they have the capacity to maintain the effectiveness balance and utilise available resources effectively as the cities grow.

Aberdeen in cluster 2 has been identified as the outlier compared to the effectiveness performance of other FUAs in the system. This is due to the geographical location of the city being strategically important to provide infrastructure and services to the oil extraction industries in the North $\mathrm{Sea}^{37}$. Although the reported oil production in the region has declined over the years, Aberdeen still possesses very high exergy intensities throughout the period as it serves as the capital of resource extraction in the region for handling inflows and outflows of oil and petroleum products. Despite the high flow activity within and beyond the city's boundaries, the GVA income generated is too low and incomparable to the resource-intensive activities in the related industries. Likewise in other developing regions where the economy of the countries mainly relies on oil exports, the resource available for extraction is limited and oil production would have to be cut in order to meet zero-carbon targets, thus the cities must diversify their economic activities away from oil extraction industries. For the example in this case, the location of the city presents an opportunity for the local planners to invest in infrastructure development and research facilities that facilitate decoupling economic growth from natural resource consumption through less resource-intensive but high-income activities.

Cluster 3 consists of two FUAs which were found to perform consistently throughout the years of this case study. Although the two areas, Edinburgh and Cheshire West and Chester, are located in two different regions, and have a considerable difference in exergy intensity and their overall resource effectiveness, both areas have experienced steady growth and minimal changes in performance over the years. This suggests their economic outputs are mainly generated from less resource-intensive activities that are less dependent on resource imports ${ }^{35}$. This justifies the consistent effectiveness performance observed in those areas despite the change in overall import and varying intensities across the whole system. In this case, strategies to promote more effective ways of resource-use to reduce total resource imports and exergy intensities in these areas would be helpful in lowering the demand for resource extraction. For example, for Cheshire West and Chester, which has higher exergy intensity and lower effectiveness, performance can be improved by having longer flow cycles through a cross-sector CE to increase utilisation and recirculation of flows within the system. It is also worth noting that although London has a similar economic focus on services-related industries, the city is subjected to a large degree of externalities and uncertainties due to high economic complexity and diversity so its performance fluctuates more than the rest of the cities in this cluster.

Although clusters 4 and 5 have very similar effectiveness trajectories and exergy intensities, a substantial difference is observed when comparing the sources of imports into the cities. The FUAs in cluster 4 have higher intercity import ratios than cluster 5 as well as any other clusters. On average, cluster 4 has the highest overall resource effectiveness and exergy intensities among all the clusters. This suggests that these areas are the 


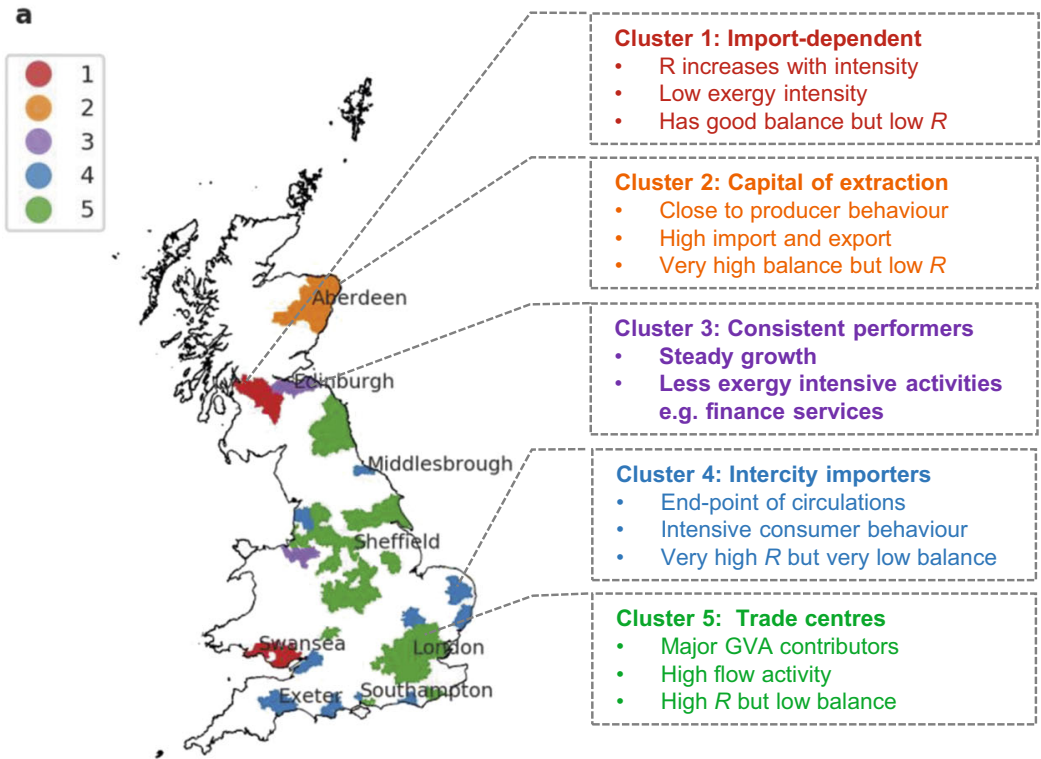

b
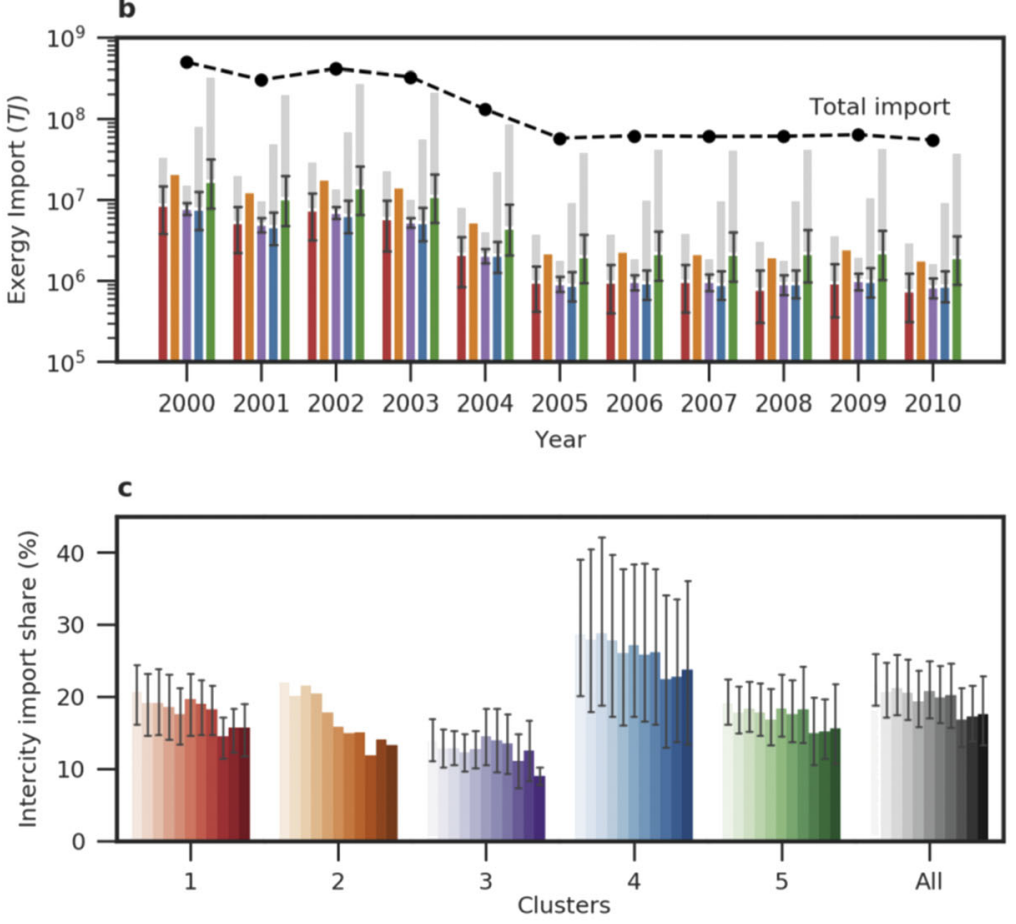
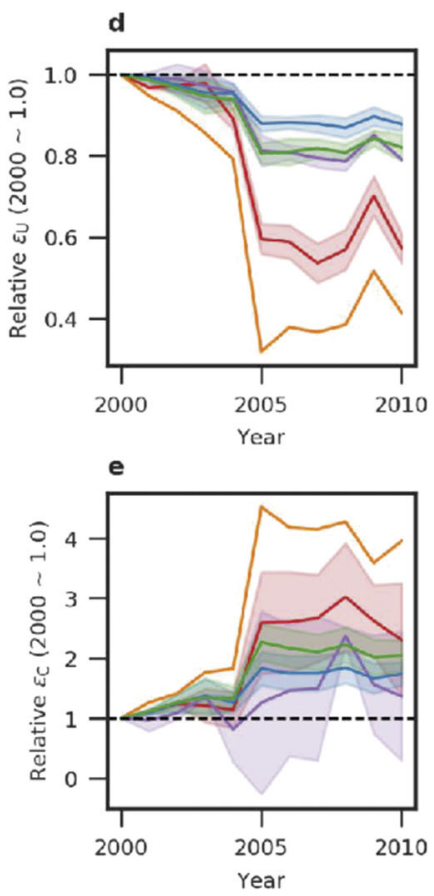

f
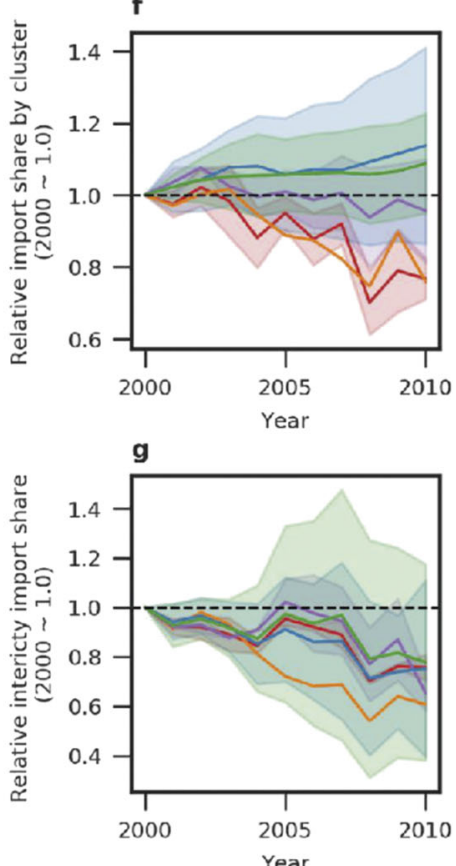

Fig. 5 Mapping the taxonomy of resource-use behaviour across the urban system of Great Britain through identifying the clustering patterns based on $\boldsymbol{R}$ and $\boldsymbol{\theta}$ results for 2000-2010. a Mapping the cluster types in the urban system of Great Britain showing the five clusters identified. The characteristics of the FUAs in a common cluster are as described in the callout boxes. The FUAs in similar clusters are colourcoded from cluster 1-5. A detailed analysis on cluster properties shows $\mathbf{b}$ the average annual resource import by each FUA using vertical coloured bars with the standard deviation shown using the error bars. The total sum of resource import by all FUAs in each of the clusters are shown using the grey bars at the back of the coloured bars representing the cluster; and c the plot of intercity import share, colour-coded based on clusters, where each bar represents the average value of the ratio of the import supplied through the intercity system over the total resource import entering an FUA with the standard deviation shown using the error bars. The colour saturation indicates the temporal transition of the case study period from 2000 (lightest saturation) to 2010 (darkest saturation). The relative changes of a selected range of cluster properties shown in the following plots: $\mathbf{d} \varepsilon_{U}, \mathbf{e} \varepsilon_{C}, \mathbf{f}$ import share (representing the fraction of the total import by the FUAs in the clusters divided by the total import by all 38 FUAs in the whole system), $\mathbf{g}$ intercity import share, are measured by comparing the resulted values to the initial values in 2000 in terms of average ratios over all FUAs in the same cluster (2000 1.0), including the standard deviation within each cluster. The plots of relative changes in $\mathbf{d}-\mathbf{g}$ show that cluster 3 (in purple) has the lowest relative changes in all aspects over the years compared to all other clusters in the system. 


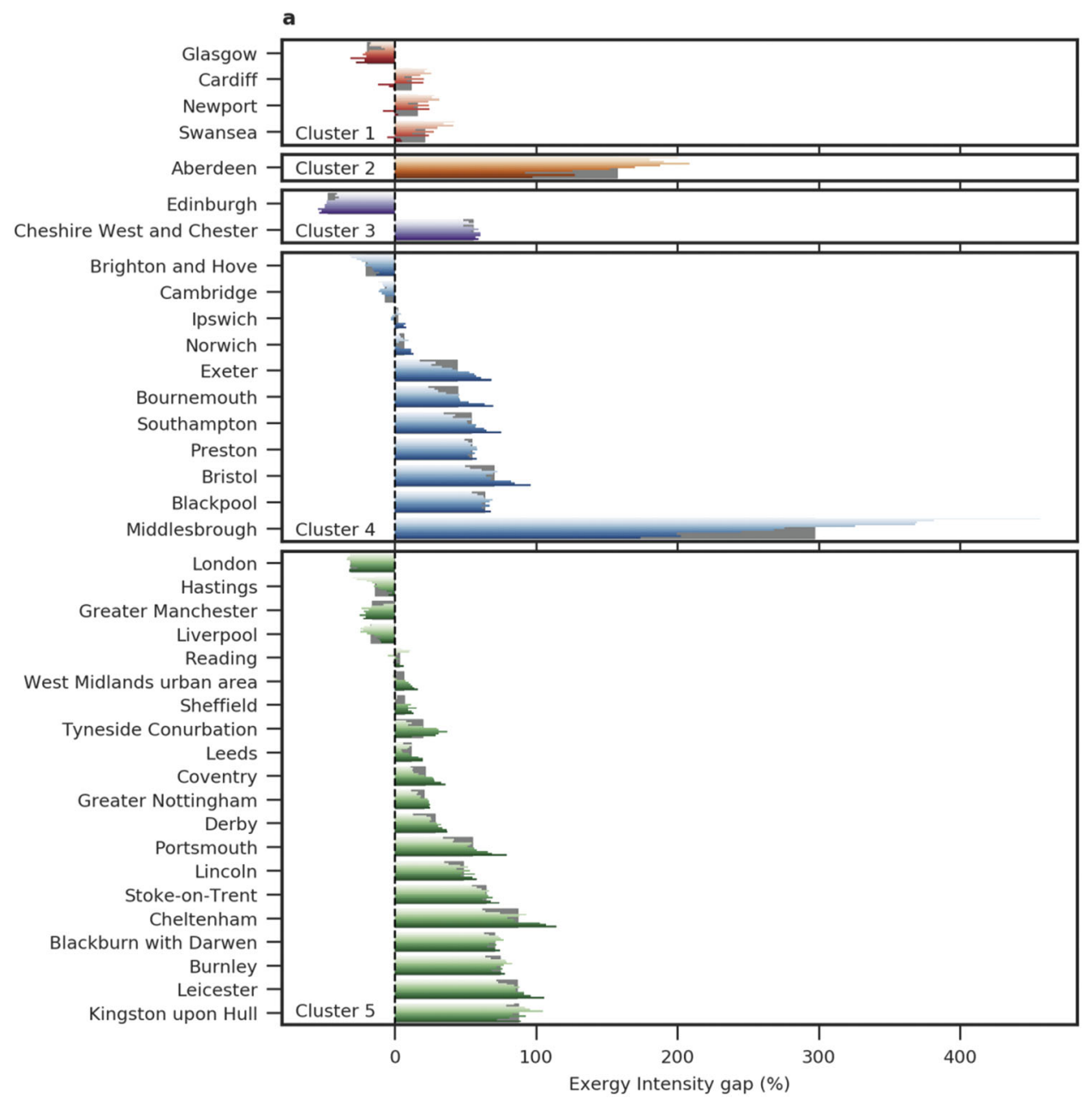

c
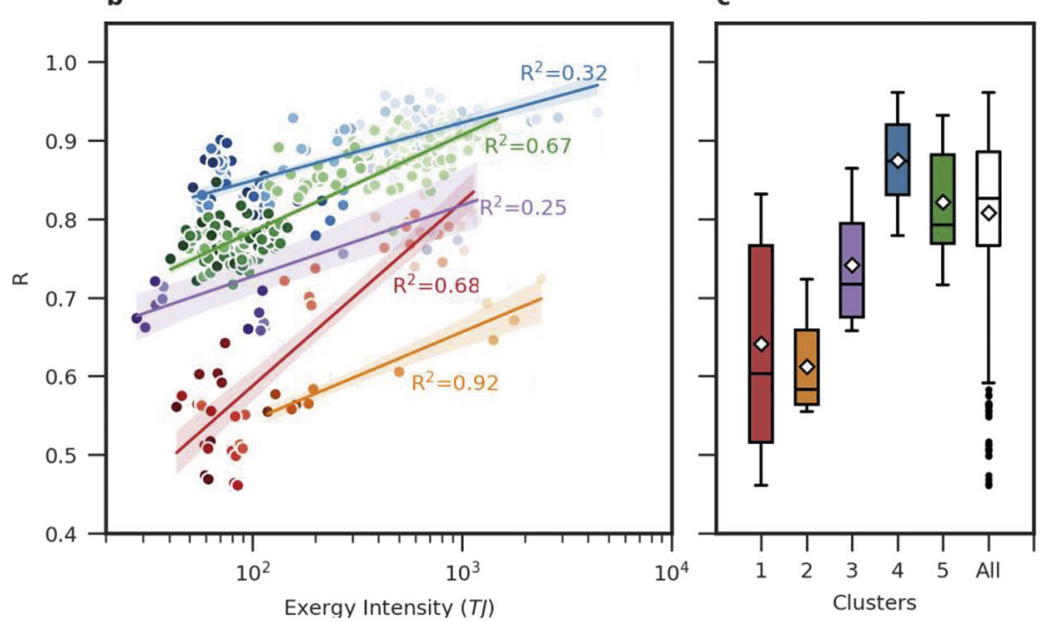

Fig. 6 Exergy intensity, exergy import per unit GVA, of all 38 FUAs, categorised and colour-coded by cluster. a Exergy intensity gap measures the percentage difference between the exergy intensity of the FUAs and the national intensity, including the average values indicated using the dark grey bar in the background. The colour saturation indicates the temporal transition of the case study period from 2000 (lightest saturation) to 2010 (darkest saturation). b Plot of the overall resource effectiveness, $R$, against the exergy import intensities for all FUAs for 2000-2010. Each scatter point represents a FUA in a year between 2000 and 2010 and the points are colour-coded by the cluster. A regression line is fitted for each cluster to show the relationship between $R$ and exergy import intensity by cluster type. This shows that the cluster 1 (in red) has the highest gradient and hence, higher dependency on the exergy import to increase the effectiveness of the FUAs in the same cluster. For all clusters, $R$ decreases with import intensity suggests that the cities are less effective when less resources are available for utilisation due to reduced imports. This means the system has high utilisation for the imported resources but lacks the ability to circulate the flows and make use of the remaining resources instead of causing more imports into the system. colour-coded box plots showing the distribution of $R$ by cluster including the combined of all FUAs in the system. Among the clusters, cluster 4 (in blue) has the highest average intensity and cluster 1 (in red) has the largest difference between the maximum and minimum values. 
major importers of intercity flows with intensive consumer traits and a very low effectiveness balance. These cities can be portrayed as the end-points of resource circulation and should be targeted for policy interventions or the introduction of strategic resource management to regulate the intake of resources by these areas and offer incentives to re-supply unused or processed materials to other cities in the system. This will facilitate a system-wide shift to CE by retaining the resources within the network for as long as possible, maximising the use of available resources. These arguments are justified by inspecting the freight traffic of major seaports in England where the ports with the highest outwards flows include Tees and Hartlepool (Middlesbrough) and Southampton which also have higher exergy intensities than the national benchmark ${ }^{38}$. In the opposite direction, high inwards traffic can be observed at Grimsby and Immingham (Kingston upon Hull) and London where both of these are important trade centres ${ }^{38}$. These cities have high inwards and outwards flow activities and are also the major contributors of the GVA. However, as the cities expand, increasing population densities and consumer incomes present an inevitable sustainability challenge due to the high carbon footprints and waste emissions ${ }^{39,40}$.

The findings reveal that most cities in GB are open system consumers relying on imports where effectiveness decreases with reducing intensities. This means the system lacks producer traits to sustain the resource-intensive activities and maintain the capacity to deliver proper services to consumers. As such, a transition to CE is imperative to maximise the use of existing resources available and reduce the import of new materials into the system when the existing resource flows are not fully utilised.

\section{Sector-level efficiencies}

Effectiveness indicators are different from efficiency as effectiveness is a system-wide performance metric to assess the portion of the total import (from outside the system) that is utilised to deliver a service or product whereas efficiency at sector-level reflects the productivity of economic activity in terms of the ratio of output produced to the aggregated inputs from all sources.

In all sectors including domestic households, the overall imports by cities have reduced and the mean efficiency has increased over the years owing to advancements in operational technologies, increased labour productivity and renewable energy harvestings. However, the results in Fig. 7 further confirmed the need for a more effective urban system. For all economic sectors, the efficiencies are relatively stable and import-independent, demonstrated by the nearly zero $R$-squared values. The saturated efficiencies can be understood as a high potential for larger work done through more effective processes to fully utilise the existing resources and reduce the demand for raw material extraction and import.

\section{DISCUSSION}

We have presented a significant conceptual advance in understanding how urban systems perform in terms of resource effectiveness through an in-depth investigation of their consumer characteristics and clustering taxonomy of resource-use. We also provided a useful tool to assess the states of resource-use in the system by measuring the differential in terms of both quantity and quality of the resources. We have shown that $G B$ has a high concentration of consumer activities in urban areas that mainly rely on the resources imported and it was found that the cities can be more resource-effective with a more diversified industrial structure. From an ecological perspective, in the absence of producers in the system, consumers will have to rely on resources imported, stressing the importance of promoting internal linkages between producers and consumers in the same urban system to maintain the ecological balance and flow circulation between cities when there are limited resources. As such, policy interventions should prioritise strategies to improve effectiveness by creating an ecological balanced and diversified economy structure offering higher chances of forming matching demand and supply of resource flows locally ${ }^{41}$. An example would be an online portal for manufacturing businesses to register their waste types and volumes to facilitate other repurposing waste ${ }^{42}$. This could be done in manufacturing clusters, at a city level, or a sub-network of closely located cities. This approach promotes longer flow circulations by connecting the local producers and consumers among the economic sectors as a lever for the transition to CE at cross-sector level, helping the cities to maximise the use of the resources available.

We have also highlighted system imbalances and drawn attention to areas which would benefit from intervention by redirecting unused resources imported elsewhere to reduce the overall imports into the system. In other words, linking the consumer cities with high imports and utilisation to producer cities with high conversion capabilities provides a pathway for sharing local resources. The study also highlights the natural geographical constraints or advantages of cities. For instance, cities like Middlesbrough, Hull and Southampton are strategically located near the coastline causing high commodity flows in these seaport areas. Another example is Aberdeen where the behaviour of the city is hugely dependent on the abundant reserve of fossil resources in the region, hence the economy is heavily affected by the fluctuations in the oil market ${ }^{43}$. The effectiveness results suggest Aberdeen possesses good balance but low effectiveness meaning the resources available were not fully utilised through the local economic activities and yet more resources are being imported into the system. A similar analysis is also applicable to other oil-rich cities in the broader contexts outside the GB urban systems, such as Houston in the United States and Abu Dhabi in the United Arab Emirates, to investigate their resource-use behaviours and economic reliance on the oil industries. Insights from such an evaluation method indicate how well the urban system performed in terms of resource effectiveness and can assist city leaders to explore the ways for better resource use and relieving their economic reliance on imports.

From a broader perspective, strategies to reduce the resource demand and consumption through better use of the existing resources available are the keys to sustainable development on a planet with finite carrying capacity. Cities are the main drivers of over-consumption and carbon emissions, as pointed out in the introduction, a systemic change of the resource-use behaviours in cities is crucial to end excessive consumption patterns beyond the planetary limits and minimise the risks of adverse environmental impacts causing biodiversity loss and climate change which affect the whole population worldwide. Characterising the behaviours of resource use and the roles of economic sectors in urban ecosystems forms an understanding of the cities' needs and their abilities to consume effectively for future growth. The OSNEA assessment will inform policymakers about an often-overlooked criterion of urban sustainability based on the effectiveness performances of the cities to utilise their limited resources available and reduce the needs to extract new resources as levers for sustainable development. This also adds to current policies and helps to facilitate decentralising of urban resource policy (from national policies) to focus on city-level planning and sectorspecific economic strategies based on their unique urban characteristics. These include regulations on how sectors connect with each other and the flow connectivity within a city, and between cities. For instance, the introduction of City Deals and Growth Deals, such as the Greater Manchester City Deal, has enabled the establishment of case-specific mechanisms, such as housing investment funds and transport proposals, to encourage local business growth and reduce carbon emissions ${ }^{44,45}$. 

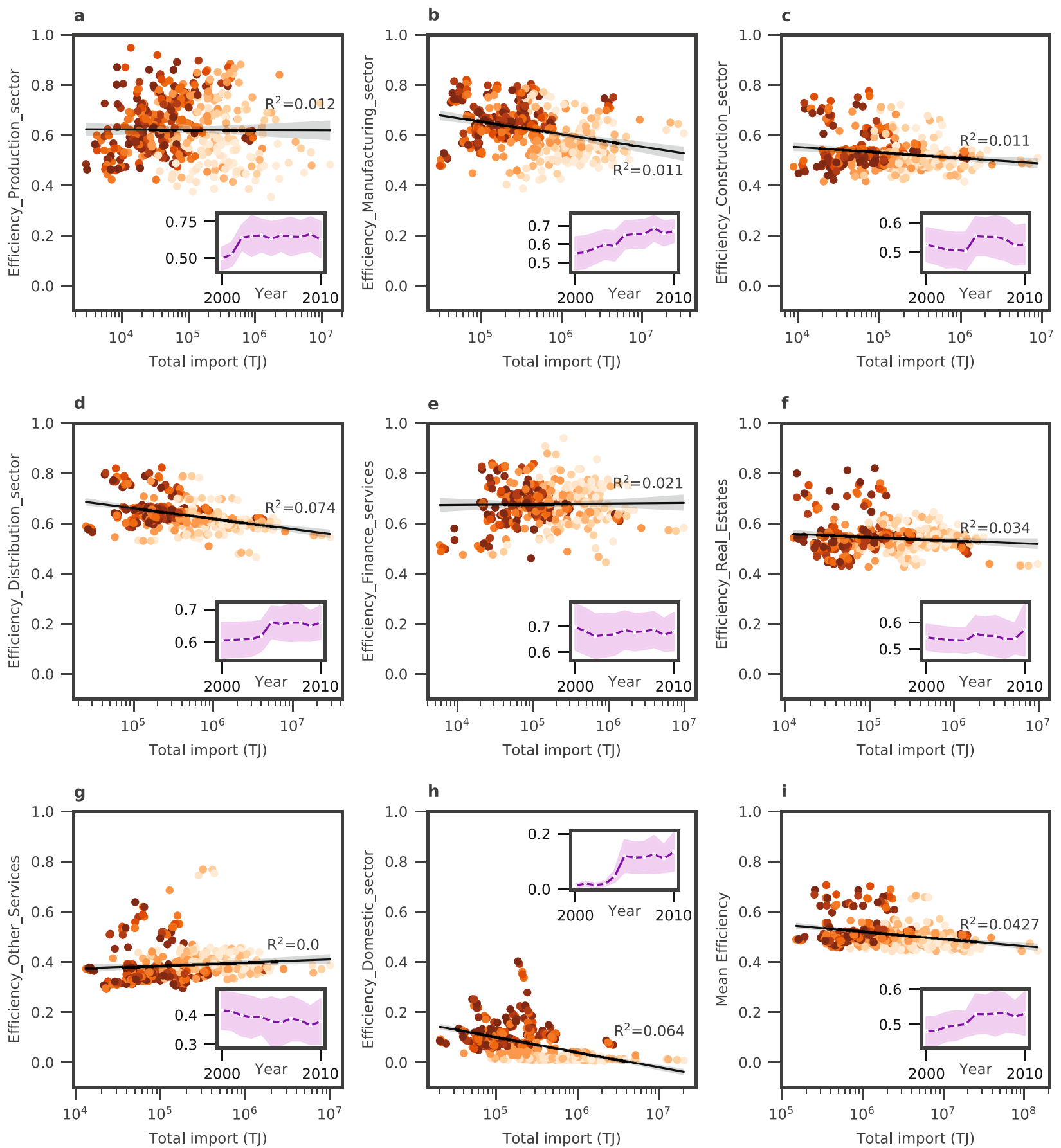

Fig. 7 Scatter plots of sector efficiencies against exergy imports by the sectors in years 2000-2010 for all FUAs in Great Britain. The marker colour saturation increases with the year from 2000 to 2010. The sectors presented here are a production, b manufacturing, c construction, (d) distribution, e finance services, $\mathbf{f}$ real estates, $\mathbf{g}$ other services and $\mathbf{h}$ the domestic sector. $\mathbf{i}$ The mean efficiency across all sectors is also included and plotted against the sum of imports by all sectors within an individual FUA. A regression line is fitted for each scatter plot. a-i A subplot with the purple line is also attached in each plot to examine the changes in annual mean efficiencies of the respective sector (also showing the standard deviation) across all FUAs in the urban system of Great Britain.

Monitoring urban metabolism is crucial to enable the shift from a linear-to-circular economy and to decouple growth from resource consumption. From a broader perspective, this study shows how the OSNEA framework can be applied to assess and monitor resource use across urban systems of various sizes and economic structures, and potentially acts as a universal tool to connect global cities to analyse the patterns of resource flows across wider regions or continents. This tool would be useful to tackle the global resource problem through an extensive application of OSNEA in the global network of urban resource flows. The effectiveness indicators $\left(\varepsilon_{U}\right.$ and $\left.\varepsilon_{C}\right)$ act as complementary measures of resource use to other indicators of resource efficiency, such as domestic material consumption, material footprint and recycling rates in the global indicator framework for monitoring the global progress towards the sustainable development goals. Together these would account for the total 
resource intakes and reflect the states of resource use in cities. For sustainable development, creating a balanced system and effective operations help to limit the resource intakes and consumption-related emissions from global cities. This work also aligns with C40's efforts on accounting sector-based greenhouse gases (GHG) emission from activities inside the cities to categorise consumer cities ${ }^{46}$. A case study of carbon accounts in the UK cities has shown that consumption-based emissions have exceeded the production-based emissions in most urban areas ${ }^{47,48}$. This agrees with our observations for the effectiveness balance where a majority of cities have higher effectiveness in resource utilisation than conversion $\left(\theta>45^{\circ}\right)$. These findings support the implementation of the 2030 Agenda for Sustainable Development accelerating the transition to CE by closing the circularity gaps in resource flows ${ }^{49}$

\section{METHODS}

\section{Overview of the OSNEA framework}

The open system network effectiveness analysis (OSNEA) was developed by Tan et al. ${ }^{27}$ as an urban sustainability assessment framework to investigate the producer and consumer behaviours of urban systems by studying the resource flow connections and the interactions between socio-economic sectors. OSNEA is an ecological-thermodynamic approach integrating thermodynamic and economic systems at the interface of human ecology and urban systems to study the metabolism of resource transformation and utilisation in cities, or in broader urban systems of connecting cities. The framework accounts for the differential in both quantity and quality of resource supplies, expressing the flows in terms of exergy to evaluate the changes in resource quality through urban processes. For the sake of completeness, extended-exergy accounting (EEA) method is also integrated in the OSNEA methodology in conjunction with exergy analysis to include additional work done contributed due to labour work and capital flows in the urban flows network ${ }^{50}$.

According to the second law of thermodynamics, entropy is produced when energy is converted to work done because in irreversible processes, not all energy can be converted into work due to their quality (usefulness) differences ${ }^{51}$. In terms of exergy, quality degradation and entropy production occur as exergy is being destroyed in a dissipative transformation process. Applying thermodynamics laws to urban ecosystems, as urban systems continue to grow, more transformation processes are developed to increase the systems' abilities to dissipate and maximise the use of resources in order to maintain their equilibrium when external inputs enter the systems ${ }^{26}$. For self-organisational open systems, the rates of entropy production and exergy destruction increase with higher resource intakes into the system ${ }^{25,52}$. Hence, the measure of resource utilisation in urban systems can be evaluated based on their abilities to dissipate and destroy exergy ${ }^{53,54}$, which is also reflected in the development and organisational level of the ecosystem. In other words, a more effective urban system has a higher capacity to destroy more exergy and maximise utilisation of the resources available ${ }^{27}$.

The methodological workflow of OSNEA consists of four key steps: firstly, an exergy-based resource accounting through yearly commodity mass import and export data for each FUA. Secondly, formulation of the input-output resource flow for exchanges of goods and services between the sectors including intercity imports and exports across the whole urban system then thirdly, assembly of an adjacency matrix based on the input-output data to construct an urban flow network for each FUA. The adjacency matrix has the same size (number of columns and rows) as the total number of nodes in the network where each node represents a sector and each element of the matrix represents a directional weighted connection between two nodes. Lastly, conduct OSNEA for each FUA to investigate the effectiveness of resource use through urban activities in those areas, and collectively, these allow us to study the behaviour of the whole urban system.

\section{Effectiveness as performance metrics}

OSNEA introduces two effectiveness indicators, namely the effectiveness of utilisation and the effectiveness of conversion, to evaluate the ability of a system to utilise or convert the resource available in the system based on the incoming cross-boundary flows. The metrics address an oftenoverlooked criterion of resource utilisation in cities by quantifying the ability of a system to extract the usefulness from high-quality resources (high exergy). The method can be used to explore how urban systems are organised to make use of the resources imported as the demand for new materials continues to grow, and to encourage more effective use of the limited resources available in order to reduce the need for raw material extraction elsewhere.

The first indicator, the effectiveness of utilisation, $\varepsilon_{\mathrm{U}}$, is a dimensionless performance metric for an urban system based on the ratio of exergy destruction to the total exergy import representing the fraction of the total resources imported that is utilised in the system to produce work done, and the second indicator, the effectiveness of conversion, $\varepsilon_{C}$, is another dimensionless performance metric for the same urban system based on the ratio of exergy export (including generation of capital funds) to the total exergy import, representing the fraction of the total resources imported that is converted to useful products for exporting purposes. Both of these indicators are expressed in terms of a fraction of the total import which can be acquired through accounting the total exergy exergetic content of incoming cross-boundary resources, $\sum F_{\text {import }_{i}}$, entering the system received by all sectors in the network. The equations for $\varepsilon_{U}$ and $\varepsilon_{C}$ are as follows:

$\varepsilon_{\mathrm{U}}=\frac{\sum_{i=1}^{m} f_{\text {destroyed }_{i}}}{\sum_{i=1}^{m} F_{\text {import }_{i}}}$

$\varepsilon_{\mathrm{C}}=\frac{\sum_{i=1}^{m} F_{\text {export }_{i}}}{\sum_{i=1}^{m} F_{\text {import }_{i}}}$

where $i$ refers to an arbitrary node of any sector in the network and $m$ is the size of the network which is equal to the total number of sectors in a city. From Eq. (1), $\varepsilon_{\cup}$ represents the portion of the resource that is utilised based on the total import and has an upper limit of 1 where $\varepsilon_{U}=0.5$ means half of the resources available is utilised and the other half is either converted to exports or emitted as waste, which can be measured with $\varepsilon_{C}$ in Eq. (2).

The efficiency results of each sector, as shown in Fig. 7, can be calculated

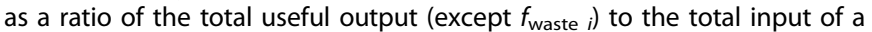
sector, representing the useful work produced with a given resource intake by the sectors in terms of exergy. The equation for the exergetic efficiency is given as:

Exergetic efficiency $=\frac{\sum f_{\text {output }_{i}}-f_{\text {wast }_{i}}}{\sum f_{\text {input }_{i}}}$.

The intensity result of each sector, including total intensity of the whole system, as shown in Fig. 4, which measures the exergy imported to generate per unit GVA in one year, can be calculated as:

Exergy intensity $=\frac{f_{\text {import }_{i}}}{\mathrm{GDP}_{i}}$.

The aggregated GVA of the FUAs investigated in this case study are acquired by summing up the GVA of the LAUs published by the Office of National Statistics (ONS) at local authority level ${ }^{35}$. See Supplementary Method 1 for more details of the exergy balance equation of the network and derivation of these metrics.

From the effectiveness results, plotting $\varepsilon_{U}$ and $\varepsilon_{C}$ on a polar coordinate system, as shown in Fig. 3a, gives the magnitude as $R$ and the angle from the horizontal axis as $\theta$ :

$$
\begin{aligned}
& R=\sqrt{\varepsilon_{\mathrm{U}}^{2}+\varepsilon_{\mathrm{C}}^{2}} \\
& \theta=\tan ^{-1} \frac{\varepsilon_{U}}{\varepsilon_{\mathrm{C}}}
\end{aligned}
$$

where $R$ is defined as the overall resource effectiveness which measures the state of resource-use by the system by considering both producer and consumer capability, while $\theta$ is the angle of overall effectiveness balance that evaluate the degree of producer and consumer behaviours exhibited by the system.

\section{Clustering classification}

The clustering patterns of the cities in the urban system can be identified by comparing the pairwise Euclidean distances between any two FUAs in each year, treating the $R$ and $\theta$ results for 2000-2010 of each FUA as individual vectors of size 11. The distance between two clusters is calculated using an average-linkage clustering method in each iteration then the results are presented in a dendrogram to show the hierarchy 
relationships among the FUAs and clusters ${ }^{55}$. The equation for calculating Euclidean distance used is given as:

Distance $=\sqrt{\sum\left(u_{i}-v_{i}\right)^{2}}$

where $u$ and $v$ represent the $R$ or $\theta$ vectors of any paired FUAs to compare their performances over the study period. The clustering groups are first identified based on the $\theta$ results, which show that Aberdeen's behaviour is substantially different (due to smaller $\theta$ ) compared to other FUAs and hence, Aberdeen is set apart from the rest of the clusters. Applying the same clustering method on the $R$ results of the whole urban system gives the clustering classification shown in Fig. 5. See Supplementary Note 1 for the clustermap showing the pairwise distances among the FUAs and the dendrogram for the clustering hierarchy. See Supplementary Note 2 for more information on clustering classification method.

\section{Data preparation and processing}

Goods import and export data, in the quantity of mass (some in the unit of energy, i.e. kilowatt-hour for traded electricity), can be acquired from the United Nations Comtrade database for international trade flows ${ }^{56}$. Commodity flows crossing the boundary of the UK, in the unit of mass, for 2000 to 2010 are considered in this study. The mass of imported and exported goods can be converted to find the equivalent amount of exergy from their respective specific exergy ${ }^{57-68}$. See Supplementary Method 2 for more details of the commodity types and their specific exergy values.

The input-output data for intra-city, intercity, inter-regional and international resource flows of the urban systems can be acquired from the EUREGIO database, a global input-output database with multi-regional details for European regions for 2000-2010 based on Eurostat Nomenclature of Territorial Units for Statistics Level 2 (NUTS 2) classification system $^{69,70}$. The input-output table of resource exchanges between the sectors, including the final demand and cross-boundary imports and exports for all three NUTS 2 regions in GB are extracted from EUREGIO global input-output table for each year in this case study. For accounting exergy import from abroad into a region, the total exergy import into the whole UK system $\left(F_{\text {import }}^{\mathrm{UK}}\right)$ is first distributed across all NUTS 2 regions in the United Kingdom according to the proportions of regional import values compared to the national import values. This is done by normalising the total exergy import by the monetary import values recorded in the input-output table to acquire a normalisation factor for the exergy value per unit monetary transaction for drawing imports into each region. For goods import, the commodities are supplied through either production or manufacturing sector into the system as the foreign supplying sector and the local receiving sector can be identified from the input-output table hence, exergy imports from production $\left(f_{\text {import }}^{\mathrm{UK}}\right)$ and manufacturing sectors $\left(f_{\text {import }}^{\cup K}\right)$ are normalised separately for different product groups.

Resource intakes by an urban system are also imported in the form of services. The extended-exergy accounting method ${ }^{71}$ is used to estimate the exergy equivalent of capital, $e_{k}$, which represent the amount of exergy required to deliver the services, measured in the unit of Joule per monetary unit. Thus, the resultant exergy imported via services $\left(f_{\text {import }}^{\cup K}{ }_{i K}\right)$ is the product of $e_{\mathrm{K}}$ and the monetary value of services imported by each FUA. Furthermore, $e_{K}$ is also used to account for the capital flows to and from the sectors and the capital reserve (node labelled as $\mathrm{K}$ ) in the city such as GVA, private expenditure consumption and gross fixed capital formation (GFCF) of the economy as shown in Fig. 2c.

To obtain the amount of inflow for each FUA, the total exergy imports, comprising imports via goods and services supplied from both the intercity system and abroad, is then scaled down from regional-level to city-level based on the GVA ratio of the importing sector in each urban area to the GVA of their respective region. More precisely, for each FUA, the total exergy import of a sector $(i), F_{\text {import; }}^{\mathrm{FUA}}$, can be computed as a fraction of the exergy imports of the whole NUTS 2 region, $F_{\text {import }}^{\text {NUTS }}{ }^{\prime}$ and the whole UK, $F_{\text {import }_{i},}^{\mathrm{UK}}$ as demonstrated in the following equations:

$F_{\text {import }_{i}}^{\mathrm{NUTS} 2}=f_{\text {import }_{i, \mathrm{P}}}^{\mathrm{NUTS}}+f_{\mathrm{import}_{i, \mathrm{M}}}^{\mathrm{NUTS} 2}+f_{\text {import }_{i, \mathrm{~K}}}^{\mathrm{NUTS}}$

where, $f_{\text {import }_{i, p}}^{\text {NUTS } 2}$ is the import from production sector,

$f_{\text {import }_{i, \mathrm{P}}}^{\mathrm{NUTS2}}=f_{\text {import }_{i, \mathrm{P}}}^{\mathrm{UK}} \times \frac{\underbrace{\mathrm{NUTS2}}_{\text {import }_{i, \mathrm{P}}}}{\underbrace{\mathrm{UK}}_{\text {import }_{i, \mathrm{P}}}}$ $f_{\text {import }_{i, M}}^{\text {NUTS } 2 ~ i s ~ t h e ~ i m p o r t ~ f r o m ~ m a n u f a c t u r i n g ~ s e c t o r, ~}$

$f_{\text {import }_{i, \mathrm{M}}}^{\text {NUTS2 }}=f_{\text {import }_{i, \mathrm{M}}}^{\mathrm{UK}} \times \frac{\underbrace{\mathrm{NUTS2}}_{\text {import }_{i, \mathrm{M}}}}{\underbrace{\mathrm{UK}}_{\text {import }_{i, \mathrm{M}}}}$,

and $f_{\text {import }}^{\text {NUTS } 2}$ is the import as services delivered,

$f_{\text {import }_{i, \mathrm{~K}}}^{\mathrm{NUTS}_{i}}=\underbrace{\mathrm{NUTS}}_{\text {import }_{i, \mathrm{~K}}} \times \mathrm{ee}_{\mathrm{K}}$.

For each FUA in each of the NUTS 2 area, the resultant import to sector $i$

$F_{\text {import }_{i}}^{\text {FUA }}=F_{\text {import }_{i}}^{\text {NUTS2 }} \times \frac{\text { GVA }_{i}^{\text {FUA }}}{\text { GVA }_{i}^{\text {NUTS2 } 2}}$.

If an FUA is located across more than one region $(a, b, \ldots N$ regions), the importing flow is scaled down using the GVA of the sector in the LAUs which is then combined to form a FUA as the resulting sum of the individual LAU:

$F_{\text {import }_{i}}^{\mathrm{FUA}}=F_{\text {import }_{i}}^{\mathrm{NUTS}_{2}} \times\left(\frac{\mathrm{GVA}_{i}^{\mathrm{LAU}_{a}}}{\mathrm{GVA}_{i}^{\mathrm{NUTS}_{2}}}+\frac{\mathrm{GVA}_{i}^{\mathrm{LAU}_{\mathrm{b}}}}{\mathrm{GVA}_{i}^{\mathrm{NUTS}_{2}}}+\ldots+\frac{\mathrm{GVA}_{i}^{\mathrm{LAU}_{N}}}{\mathrm{GVA}_{i}^{\mathrm{NUTS}_{2}}}\right)$.

The total incoming resource flows into each FUA is the sum of the intercity supplies (IC) from other FUAs in the same urban system and imports from abroad $(A)$ such that:

$F_{\text {import }_{i}}^{\mathrm{FUA}}=F_{\text {import }_{i}(\mathrm{IC})}^{\mathrm{FUA}}+F_{\text {import }_{i}(\mathrm{~A})}^{\mathrm{FUA}}$.

Therefore, operations in Eqs. (8-13) are conducted to compute both $F_{\text {import }_{i} \text { (IC) }}^{\mathrm{FUA}}$ and $F_{\text {import }_{i} \text { (A) }}^{\mathrm{FUA}}$ for each FUA in the case study. Due to the lack of data for accounting, the actual commodity flows between the cities at the present time, the same normalisation factors (for the respective products imported from production or manufacturing sectors) are used for accounting intercity imports and exports. This essentially assumes that the goods import from other cities have the same exergy content per unit monetary flow as the import from abroad. In addition, exergy flow from the environment through local production within the FUA is assumed to be negligible in this study because the main extraction activities, such as agriculture, mining and forestry activities, are performed outside the urban areas and the extracted materials are being supplied to the city through intercity imports.

Similar accounting methods as for the imports in Eqs. (8-14) is repeated for computing total exergy exports from the FUAs. As the system is bounded by the thermodynamic limits following the law of energy conservation, in the urban system, the outflow exergy is always lower than the inflow exergy due to resource utilisation and waste emissions from the transformation processes within the system. Otherwise, we assume fossil fuel products (documented in Chapter 27 of the harmonised commodity description and coding system for international trade flows ${ }^{72}$ ) can be excluded from the exports to ensure the flows in the system are conserved. For the same reason, fossil fuel products are excluded from the intercity exports to other areas because the production of such products is often performed outside the urban areas. For other products, good exports supplied from production and manufacturing sectors are calculated in a similar manner as the imports using the mass export data obtained from the United Nations Comtrade database ${ }^{56}$ and the specific exergy value of the commodities. Services exported from the FUA are amounted in terms of extended-exergy outflows using ee $_{k}$.

According to Leontief's model ${ }^{73}$, the input-output transactions between the sectors form a bi-directional network of intra-system resource flows. The network can be expressed as an adjacency matrix with the same size as the number of sectors in the system. The final form of an assembled exergy-based input-output matrix, $\mathbf{M}_{\mathrm{ex}}$, tabulates resource exchanges within the system, and between the systems of cities, in terms of a combination of exergy and extended-exergy flows. The values of total exergy import entering the system (through all importing sectors), $F_{\text {import }}^{\text {FUA }}$, form a flow vector, $\mathbf{F}$, which is then distributed from the importing sectors to other sectors accordingly to the import supply ratio stated in the normalised input-output matrix, $\mathbf{M}_{i j}$, based on the sum of all monetary imports received by each sector from the intercity system and abroad. Hence, the equation is:

$\mathbf{M}_{\mathrm{ex}}=\operatorname{diag}(\mathbf{F}) \mathbf{M}_{i j}$.

From household activities, the exergy equivalent of labour output contribution from the domestic sector via employment by each sector can be calculated from ee $e_{\mathrm{L}}$, which is defined as the amount of exergy required 
to contribute one hour of work for each worker ${ }^{71}$. To calculate the total labour output of the domestic sector (indicated as output flows from node Do in Fig. 2), ee $e_{L}$ is multiplied by the total number of employees and the total number of working hours in a year, which varies by sector types. Employment data, including the number of employees and the average work hours by sector, can be obtained from the $\mathrm{ONS}^{74}$. However, these data are only available for regional statistics hence, the numbers are scaled down to FUA and LAU levels using the GVA ratios. In some exceptional cases where the regional employment data is unavailable for a specific sector, the national median values are used.

From the adjacency matrix, together with exergy import, $\sum F_{\text {import }}$, and export data, $\sum F_{\text {export }}$, the total resource input, $\sum f_{\text {input }}$, and output, $\sum f_{\text {output }}$, of each sector can be computed. Taking the net difference between the input and output gives the amount of exergy destroyed, $f_{\text {destroyed }_{i}}$, at each sector as the resources are being utilised locally. To account for the waste exergy, $\sum f_{\text {waste }_{i}}$ economy-wide estimates can be calculated by using an emission factor as a coefficient to convert activity statistics to GHG emissions ${ }^{75}$ such that:

Emission $=$ Factor $\times$ Activity

For example, the emission factor for carbon dioxide, $\mathrm{CO}_{2}$, measures the amount of $\mathrm{CO}_{2}$ released to the atmosphere, in terms of the equivalent mass and exergy of $\mathrm{CO}_{2}$ produced by a unit of activity conducted such as energy combustion or electricity generation ${ }^{76}$. In this study, GHG emissions based on the activities of exergy imports (measured in the unit of Joule) by the industries are calculated by using the GHG emissions intensity data of UK energy use for $2000-2010^{77}$. These essentially give the required data and information for evaluating system effectiveness and sector efficiency to study the cities performance and resource-use behaviours of the system, as well as computing the intensity of exergy import compared to the economic benefits the sector has generated. In future work, the analysis can be expanded by incorporating an exergy accounting of waste emissions in the methodology to include all types of waste streams exiting the system when the data becomes available.

The main limitation of this study is the lack of stock properties in the model due to insufficient data on local inventory for all FUAs in the system hence neglecting resource accumulations and storage units (such as built environment) in the system. Further improvement should integrate storage characteristics in the model to simulate temporal and spatial variations of resource stocks and flows of an urban system when the data becomes available. For example, accounting of building stocks in cities requires an extensive database of building information such as material types, floor areas, purposes and ages. This could lead to an insightful understanding of how cities utilise their existing stocks and help to locate unused resources in the systems for more effective use of all available resources. Moreover, normalising resource intakes with GVA of the industries or population size of the cities provides new dimensions to the analysis to consider alternative measures of resource productivity in cities and to inform decision making, adding other policy options to drive urban development towards a sustainable future.

Furthermore, the thermodynamic analogy of cities as open systems provides an interface for integration of thermodynamic and economic systems, in the form of open system networks, to understand the effectiveness and behaviours of resource use through urban metabolic processes. However, the real implication of OSNEA application is limited because the use of thermodynamic principles to model the resemblance between resource use in urban systems and transformation in energy systems is regarded as metaphorical ${ }^{78}$. The use of exergy and extended-exergy in this study provide a descriptor to evaluate the theoretical maximum work extractable from the resources available, often expressed in terms of work availability or value of monetary benefits, to monitor the effectiveness and overall resource efficiency of the system, but the method does not reflect work done and justifiable execution in reality ${ }^{79}$. Hence, this should be taken into consideration when applying the framework in real-world situations.

\section{Reporting summary}

Further information on research design is available in the Nature Research Reporting Summary linked to this article.

\section{DATA AVAILABILITY}

The data generated and analysed during this study are described in the following data record: https://doi.org/10.6084/m9.figshare.13312313 ${ }^{80}$. Seven datasets were generated in this study and are shared openly as part of the data record. All datasets are named according to the terminology used in the related article. The datasets are as follows: Comtrade_data_UK (supporting a method in the Supplementary Information), Effectiveness_results.txt (supporting Figs. 3, 5, 6), Efficiency_fua.txt (supporting Fig. 7), Exergy_conversion.xlsx (supporting a method in the Supplementary Information), Export by sector.csv (supporting Fig. 4), Import by sector.csv (supporting Figs. 4-6), ONS_data_UK.xIsx (supporting Figs. 4-6).

\section{CODE AVAILABILITY}

The codes used in this study are available from the corresponding author upon reasonable request.

Received: 21 April 2020; Accepted: 5 December 2020; Published online: 27 April 2021

\section{REFERENCES}

1. Swilling, M. et al. The Weight of Cities: Resource Requirements of Future Urbanization (UN Environment - International Resource Panel, 2018).

2. Rockström, J. et al. Planetary boundaries: exploring the safe operating space for humanity. Ecol. Soc. 14, 32 (2009).

3. International Resource Panel. Assessing Global Resource Use: A Systems Approach to Resource Fficiency and Pollution Reduction (IRP, 2017).

4. Forward, B. F. City Limits: A Resource Flow and Ecological Footprint Analysis of Greater London (Chartered Institution of Wastes Management Environmental Body, 2002).

5. Bioregional. One planet Living - a sustainability framework by Bioregional. Bioregional https://www.bioregional.com/one-planet-living (2018).

6. United Nations. The Sustainable Development Goals Report 2019 (United Nations Department of Economic and Social Affairs, 2019).

7. Wolman, A. The metabolism of cities. Sci. Am. 213, 179-190 (1965).

8. Musango, J. K., Currie, P. \& Robinson, B. Urban Metabolism for Resource-Efficient Cities: From Theory to Implementation (UN Environment, 2017).

9. Fath, B. D. \& Patten, B. C. Review of the foundations of network environ analysis. Ecosystems 2, 167-179 (1999).

10. Zhang, Y. et al. Development of a spatially explicit network model of urban metabolism and analysis of the distribution of ecological relationships: case study of Beijing, China. J. Clean. Prod. 112, 4304-4317 (2016).

11. Tan, L. M. et al. Ecological network analysis on intra-city metabolism of functional urban areas in England and Wales. Resour. Conserv. Recycl. 138, 172-182 (2018).

12. Huang, S.-L. \& Hsu, W. L. Materials flow analysis and emergy evaluation of Taipei's urban construction. Landsc. Urban Plan. 63, 61-74 (2003).

13. Fischer-Kowalski, M. et al. Methodology and indicators of economy-wide material flow accounting. J. Ind. Ecol. 15, 855-876 (2011).

14. Calvo, G., Valero, A. \& Valero, A. Thermodynamic approach to evaluate the criticality of raw materials and its application through a material flow analysis in Europe. J. Ind. Ecol. 22, 839-852 (2018).

15. Goldstein, B., Birkved, M., Quitzau, M.-B. \& Hauschild, M. Z. Quantification of urban metabolism through coupling with the life cycle assessment framework: concept development and case study. Environ. Res. Lett. 8, 035024 (2013).

16. Mirabella, N., Allacker, K. \& Sala, S. Current trends and limitations of life cycle assessment applied to the urban scale: critical analysis and review of selected literature. Int. J. Life Cycle Assess. 24, 1174-1193 (2019).

17. Zhang, L., Hu, Q. \& Zhang, F. Input-output modeling for urban energy consumption in Beijing: dynamics and comparison. PLOS ONE 9, e89850 (2014).

18. Zheng, $H$. et al. Linking city-level input-output table to urban energy footprint: construction framework and application. J. Ind. Ecol. 23, 781-795 (2019).

19. Newell, J. P., Goldstein, B. \& Foster, A. A 40-year review of food-energy-water nexus literature and its application to the urban scale. Environ. Res. Lett. 14, 073003 (2019)

20. Girardet, H. The Gaia Atlas of Cities: New Directions for Sustainable Urban Living. (Gaia, 1996).

21. Huang, S.-L. Urban ecosystems, energetic hierarchies, and ecological economics of Taipei metropolis. J. Environ. Manage. 52, 39-51 (1998).

22. Bai, X. Industrial Ecology and the Global Impacts of Cities. J. Ind. Ecol. 11, 1-6 (2007).

23. C40. Municipality-led circular economy case studies in partnership with the Climate-KIC Circular Cities Project (2018).

24. Salat, S. \& Loeiz, B. Scaling, exergy and urban efficiency. In Proceedings of the 2nd International Exergy, Life Cycle Assessment and Sustainability Workshop \& Symposium (ELCAS-2) under the frame of the "European Cooperation in Science and Technology" and UNEP/SETAC Life Cycle Initiative, Nisyros, Greece (2011).

25. Schneider, E. D. \& Kay, J. J. Life as a manifestation of the second law of thermodynamics. Math. Comput. Model. 19, 25-48 (1994). 
26. Kay, J. J. A nonequilibrium thermodynamic framework for discussing ecosystem integrity. Environ. Manage. 15, 483-495 (1991).

27. Tan, L. M., Arbabi, H., Brockway, P. E., Densley Tingley, D. \& Mayfield, M. An ecological-thermodynamic approach to urban metabolism: Measuring resource utilization with open system network effectiveness analysis. Appl. Energy 254, 113618 (2019).

28. Hammond, G. P. Industrial energy analysis, thermodynamics and sustainability. Appl. Energy 84, 675-700 (2007).

29. Zvolinschi, A., Kjelstrup, S., Bolland, O. \& van der Kooi, H. J. Exergy sustainability indicators as a tool in industrial ecology. J. Ind. Ecol. 11, 85-98 (2007).

30. Sciubba, E. \& Wall, G. A brief commented history of exergy from the beginnings to 2004. Int. J. Thermodyn. 10, 1-26 (2007).

31. Office for National Statistics. Geoportal Office for National Statistics. Functional Urban Area Boundaries, Urban Audit Functional Urban Areas in Great Britain as at 31 December 2011. http://geoportal.statistics.gov.uk/datasets/urban-audit-vfunctional-urban-areas-december-2011-boundaries?geometry $=-14.079 \%$ 2C50.169\%2C16.133\%2C54.844 (2017).

32. Eurostat. Glossary: Functional urban area. Stat. Explain. https://ec.europa.eu/ eurostat/statistics-explained/index.php/Glossary:Functional_urban_area (2017).

33. Chen, N. \& Novy, D. Gravity, trade integration, and heterogeneity across industries. J. Int. Econ. 85, 206-221 (2011).

34. Oil and Gas Authority. Oil and Gas Authority Open Data. UKCS Production https:// data-ogauthority.opendata.arcgis.com/pages/production (2020).

35. Office for National Statistics. Regional GVA(I) by local authority in the UK. Dataset https://www.ons.gov.uk/economy/grossvalueaddedgva/datasets/ regionalgvaibylocalauthorityintheuk (2017).

36. McCann, P. The UK Regional-National Economic Problem: Geography, Globalisation and Governance (Routledge, 2016). https://doi.org/10.4324/9781315627151.

37. BP. North Sea portfolio. Where we operate https://www.bp.com/en_gb/unitedkingdom/home/where-we-operate/north-sea/north-sea-portfolio.html (2019).

38. Department for Transport. Port and domestic waterborne freight statistics: data tables (PORT). Statistical data set https://www.gov.uk/government/statisticaldata-sets/port-and-domestic-waterborne-freight-statistics-port (2018).

39. Pichler, P. P. et al. Reducing urban greenhouse gas footprints. Sci. Rep. 7, 14659 (2017)

40. Wiedmann, T. \& Lenzen, M. Environmental and social footprints of international trade. Nat. Geosci. 11, 314-321 (2018).

41. Arbabi, H. et al. On the use of random graphs in analysing resource utilization in urban systems. R. Soc. Open Sci. 7, 200087 (2020).

42. Domenech, T., Bleischwitz, R., Doranova, A., Panayotopoulos, D. \& Roman, L. Mapping Industrial symbiosis development in Europe_typologies of networks, characteristics, performance and contribution to the circular economy. Resour. Conserv. Recycl. 141, 76-98 (2019)

43. Smith, S. How has the oil price fall hit Scotland's north east? BBC News https:// www.bbc.co.uk/news/uk-scotland-35300495 (2016).

44. Greater Manchester Combined Authority. Greater Manchester City Deal (2012).

45. Harding, A. et al. Cities and Public Policy: A Review Paper (2015).

46. C40. Consumption-Based GHG Emissions of C40 Cities (2018).

47. Barrett, J. R. et al. Consumption-based GHG emission accounting: a UK case study. Clim. Policy 13, 451-470 (2013).

48. Sudmant, A., Gouldson, A., Millward-Hopkins, J., Scott, K. \& Barrett, J. R. Producer cities and consumer cities: Using production- and consumption-based carbon accounts to guide climate action in China, the UK, and the US. J. Clean. Prod. 176, 654-662 (2018)

49. United Nations. In A New Era in Global Health (Springer Publishing Company, 2018). https://doi.org/10.1891/9780826190123.ap02.

50. Sciubba, E. Beyond thermoeconomics? The concept of Extended Exergy Accounting and its application to the analysis and design of thermal systems. Exergy. An Int. J. 1, 68-84 (2001).

51. Rant, Z. Exergy. a New Word For Technical Available Work. Forsch. Ing. Wis. 22, 36-37 (1956).

52. Schneider, E. D. \& Kay, J. J. Complexity and thermodynamics. Towards a new ecology. Futures 26, 626-647 (1994)

53. Kay, J. J., Regier, H. A., Boyle, M. \& Francis, G. An ecosystem approach for sustainability: addressing the challenge of complexity. Futures 31, 721-742 (1999).

54. Muller, F. Handbook of Ecosystem Theories and Management (CRC Press, 2000).

55. Müllner, D. Modern Hierarchical, Agglomerative Clustering Algorithms. Technical Report (2011).

56. United Nations Department of Economic and Social Affairs. UN Comtrade Data base Trade Statistics. https://comtrade.un.org/data/ (United Nations, 2018).

57. Szargut, J. Exergy Method: Technical and Ecological Applications. International Series on Developments in Heat Transfer (WIT Press, 2005).

58. Morris, D. R. \& Szargut, J. Standard chemical exergy of some elements and compounds on the planet earth. Energy 11, 733-755 (1986).
59. Ayres, R. U., Ayres, L. W. \& Masini, A. in Sustainable Metals Management: Securing our Future - Steps Towards a Closed Loop Economy (eds von Gleich, A., Ayres, R. U. \& Gößling-Reisemann, S.) 141-194 (Springer Netherlands, 2006). https://doi.org/ 10.1007/1-4020-4539-5 6.

60. Energy Statistics Division. Energy Statistics Manual (International Energy Agency, Statistical Office of the European Communities, Organisation for Economic Cooperation and Development, 2005).

61. Dewulf, J. \& Van Langenhove, H. Thermodynamic optimization of the life cycle of plastics by exergy analysis. Int. J. Energy Res. 28, 969-976 (2004).

62. Koroneos, C. \& Kalemakis, I. Exergy indicators in the building environment. Int. J. Exergy 11, 439 (2012)

63. Truttmann, N. \& Rechberger, H. Contribution to resource conservation by reuse of electrical and electronic household appliances. Resour. Conserv. Recycl. 48 249-262 (2006)

64. Dewulf, J., Van Langenhove, H. \& Van De Velde, B. Exergy-based efficiency and renewability assessment of biofuel production. Environ. Sci. Technol. 39, 3878-3882 (2005).

65. Song, G., Shen, L. \& Xiao, J. Estimating specific chemical exergy of biomass from basic analysis data. Ind. Eng. Chem. Res. 50, 9758-9766 (2011).

66. Manso, R., Sousa, T. \& Domingos, T. Do the different exergy accounting methodologies provide consistent or contradictory results? A case study with the Portuguese agricultural, forestry and fisheries sector. Energies 10, 1219 (2017).

67. Health Promotion Board. Energy \& nutrient composition of food. Singapore Gov. https://focos.hpb.gov.sg/eservices/ENCF/ (2011).

68. Eboh, F. C., Ahlström, P. \& Richards, T. Estimating the specific chemical exergy of municipal solid waste. Energy Sci. Eng. 4, 217-231 (2016).

69. Thissen, M., Lankhuizen, M., van Oort, F., Los, B. \& Diodato, D. EUREGIO: The Construction of a Global IO Database With Regional Detail for Europe for 2000-2010. SSRN Electron. J. https://doi.org/10.2139/ssrn.3285818 (2018).

70. PBL Netherlands Environmental Assessment Agency. PBL EUREGIO. Dataset https://data.overheid.nl/dataset/pbl-euregio-database-2000-2010 (2018).

71. Sciubba, E. A revised calculation of the econometric factors $\alpha-$ and $\beta$ for the extended exergy accounting method. Ecol. Modell. 222, 1060-1066 (2011).

72. World Customs Organization. Nomenclature and Classification of Goods HS Nomenclature 2017 edition. http://www.wcoomd.org/en/topics/nomenclature/ instrument-and-tools/hs-nomenclature-2017-edition/hs-nomenclature-2017edition.aspx (2017).

73. Leontief, W. \& Leontief, W. W. Input-Output Economics (Oxford University Press, 1986).

74. Office for National Statistics. Employee Earnings in the UK Statistical Bulletins. Earnings and Working Hours. https://www.ons.gov.uk/employmentandlabourmarket/ peopleinwork/earningsandworkinghours/bulletins/annualsurveyofhoursandearnings/ previousReleases (2019).

75. National Atmospheric Emission Inventory. Emission Factors https://naei.beis.gov. uk/data/emission-factors (Department for Business, Energy and Industrial Strategy, 2017).

76. Ji, X., Chen, G. Q., Chen, B. \& Jiang, M. M. Exergy-based assessment for waste gas emissions from Chinese transportation. Energy Policy 37, 2231-2240 (2009).

77. Office for National Statistics. Atmospheric emissions: greenhouse gases by industry and gas. Dataset https://www.ons.gov.uk/economy/environmentalaccounts/datasets/ ukenvironmentalaccountsatmosphericemissionsgreenhousegasemissionsbyeconomicsectorandgasunitedkingdom (2019).

78. Hammond, G. P. \& Winnett, A. The Influence of thermodynamic ideas on ecological economics: an interdisciplinary critique. Sustainability 1, 1195-1225 (2009).

79. Söllner, F. A reexamination of the role of thermodynamics for environmental economics. Ecol. Econ. 22, 175-201 (1997).

80. Tan, L. M., Arbabi, H., Densley Tingley, D., Brockway, P. E. \& Mayfield, M. Metadata record for the manuscript: mapping resource effectiveness across urban systems. figshare https://doi.org/10.6084/m9.figshare.13312313 (2020).

\section{ACKNOWLEDGEMENTS}

Ling Min Tan acknowledges scholarship support from the Grantham Centre for Sustainable Futures, funded through the Grantham Foundation for the Protection of the Environment. Hadi Arbabi's time was supported by EPSRC awards EP/S016627/1 and EP/V012053/1. Paul Brockway's time was funded under EPSRC Fellowship award EP/R024251/1.

\section{AUTHOR CONTRIBUTIONS}

L.M.T., H.A. and M.M. have designed the study. L.M.T. has undertaken the study and wrote the manuscript. H.A., D.D.T., P.E.B. and M.M. contributed to the discussion and the manuscript. All authors have given approval to the final version of the manuscript. 


\section{COMPETING INTERESTS}

The authors declare no competing interests.

\section{ADDITIONAL INFORMATION}

Supplementary information is available for this paper at https://doi.org/10.1038/ s42949-020-00009-3.

Correspondence and requests for materials should be addressed to L.M.T.

Reprints and permission information is available at http://www.nature.com/reprints

Publisher's note Springer Nature remains neutral with regard to jurisdictional claims in published maps and institutional affiliations.
Open Access This article is licensed under a Creative Commons Attribution 4.0 International License, which permits use, sharing, adaptation, distribution and reproduction in any medium or format, as long as you give appropriate credit to the original author(s) and the source, provide a link to the Creative Commons license, and indicate if changes were made. The images or other third party material in this article are included in the article's Creative Commons license, unless indicated otherwise in a credit line to the material. If material is not included in the article's Creative Commons license and your intended use is not permitted by statutory regulation or exceeds the permitted use, you will need to obtain permission directly from the copyright holder. To view a copy of this license, visit http://creativecommons. org/licenses/by/4.0/.

(c) The Author(s) 2021 